\title{
Capital culinário: o círculo dos alimentos nos meios de comunicação
}

\author{
Cynthia Arantes Ferreira Luderer
}

NACCARATO, P.; LeBESCO, K.

Culinary capital.

London/New York: BERG, 145p., 2012.

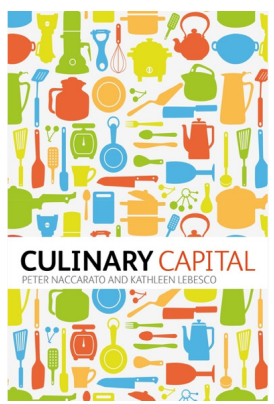

Resumo: Culinary capital é um conceito que, apoiado na teoria do capital de Bourdieu, enuncia a rede social pela qual transpassa o alimento em sua condição material ou simbólica. Com foco na cultura norte-americana, os autores discorrem sobre os discursos que transitam em torno do aumento do capital culinário e que convoca os sujeitos à cidadania pela via das regras que pregam a boa saúde. Como base para discussão, vários suportes comunicativos pelos quais transita o capital culinário são discutidos, como programas de televisão, redes sociais, sites, eventos, grupos sociais e empresas.

Palavras- chave: capital culinário; mídias; alimentação

Abstract: Culinary Capital: the circle of food in the mass media - Culinary capital, a concept based on Bourdieu's theory of cultural capital, describes the social network involving food in its material or symbolic condition. Focusing on American culture, the authors expound upon the discourses surrounding the increase in culinary capital, which summons people to citizenship via the rules they preach about good health. The discussion is underpinned by various communication media through which culinary capital is broadcast, such as television programs, social networks, websites, events, social groups, and companies.

Keywords: culinary capital; media; food 
Culinary capital é um conceito, apresentado pelos pesquisadores norte-americanos Peter Naccarato e Kathleen LeBesco, que demonstra a conexão da alimentação contemporânea com outras áreas que permeiam a economia e a cultura. O termo está apoiado no conceito de capital, sistematizado por Bourdieu, o qual seria expresso pela imbricação de vários capitais simbólicos, além do econômico, pelos quais o indivíduo adquiriria status e poder (p. 2), logo. O capital culinário estaria relacionado aos fatores que englobam a comida e as práticas alimentares.

O primeiro capítulo apresenta o novo conceito e os autores que oferecem o embasamento teórico. Foucault (p. 4) é um dos citados, pois as normativas que cerceiam a área da alimentação e que fazem parte do capital culinário são abordadas pelo conceito de biopoder. Por esse viés, são discutidas no texto as expectativas sociais dos indivíduos que, ao manterem boas práticas alimentares, tornar-se-iam bons cidadãos (p. 5).

A partir do conceito de capital, os autores ilustram a luta de classes em torno do capital culinário, expondo como as práticas sociais alimentares e os descumprimentos das classes trabalhadoras em relação à sobriedade imposta pelos que se mantêm no poder (p. 5). Nesse ínterim, os onívoros são apontados como uma elite, dada a gama de experiências gustativas que possuem. (p.09).

Os autores enunciam os vários circuitos sociais por onde transpassa o capital culinário, quer pelas vias materiais ou simbólicas. Assim, o segundo capítulo destaca o gênero feminino e os benefícios da etnia branca no mercado da alimentação. Nele são tratadas as ações comunicacionais divulgadas pelos sites de lojas de conveniência e o uso dos códigos semióticos aplicados para convocar as mulheres brancas a consumir produtos sofisticados e saudáveis. Ao atenderem essas convocações, esse grupo de consumidoras seguiriam os princípios regidos por uma cidadania que, vinculada aos discursos promovidos pelo biopoder, preza pelas boas práticas alimentares, pela boa saúde e pelo bem estar dos sujeitos. (p. 34).

No capítulo três, são discutidos os programas de televisão especializados em culinária. Apoiados em Signe Rousseau, autora de Food Mídia, os autores destacam uma crítica sobre o tema: "quanto mais consumimos a mídia relacionada à alimentação, menos incentivo temos para pensar sobre o que comemos" (p. 44).

No texto são enfatizados os programas que seguem o modelo competitivo que, por apresentarem discursos de desafio e perseverança, são apontados como os que ressaltam aspectos masculinos. Situação inversa é sinalizada pelos autores quando se referem aos programas com temáticas relacionadas à família, à hospitalidade ou às obrigações sociais, que são vistas como dedicadas ao público feminino.

A presença dos especialistas nos programas, inclusive os chefs celebridades, é também discutida. Para os autores, os chefs fortalecem o modelo do entretenimento que favorece o discurso do "como viver", enquanto "o cozinhar" passa a segundo plano (p.48). Para os dois pesquisadores, o consumidor torna-se um produto para ser usado pela mídia, 
e ela o cria para que os negócios em torno da comida sejam acelerados. Desse modo, os canais de televisão norte-americanos de culinária criam discursos com a finalidade de produzir um consumidor cidadão, que "reproduza um estilo de vida e partilhe seu status pelo consumo" (p. 50). Assim, com a divulgação das novas práticas alimentares oferecidas pela mídia, ao invés do consumidor desafiar as ideologias mantidas pelas classes dominantes, mantém-se na condição de um consumidor iludido pelo possível acesso a uma posição vinculada ao capital culinário (p.52).

O quarto capítulo apresenta a elite formada por chefs, restauranteurs, críticos e consumidores que, como especialistas e autoridades, influenciam outros atores sociais e regulam o capital culinário. As redes sociais também são tratadas a partir do papel que exercem ao fragilizar os discursos hegemônicos dessa elite. Porém, essas mensagens vinculadas por blogueiros e amadores, quando espalhadas nas redes, acabam favorecendo o mercado, pois os comentários geram a impressão, para o consumidor, de que as opiniões expostas ali são mais abertas e honestas do que as críticas dos especialistas (p. 72).

O último capítulo trata das feiras e festas populares, eventos organizados pelo poder público, que atendem a uma camada mais pobre da população. Ali os cidadãos transgridem as regras da boa saúde (p. 89), pois "a feira passa a ser uma licença para abandonar as normativas dos comportamentos alimentares, e permitem divertir-se no exótico, com alimentos não saudáveis e excesso de consumo" (p. 92). A heresia carnavalizada é endossada por competições de comilões, que se tornam atração, e que são retransmitidas pela rede de televisão esportiva ESPN, na condição de um esporte.

Por meio desse compêndio, além de ser possível verificar o papel do capital culinário, como um norteador da dinâmica paisagem culinária presente na sociedade contemporânea, pode-se verificar que "a mídia rapidamente se adapta pelos caminhos que respondem aos desejos e demandas da audiência" (p. 119).

Cynthia Arantes Ferreira Luderer é mestre e doutora em Comunicação e Semiótica na PUC-SP; é especialista em Gestão em Qualidade. Historiadora, Pedagoga e Tecnóloga em Gastronomia; é professora da Unimonte

cynthialud@gmail.com 